University of South Carolina

Scholar Commons

1995

\title{
A Boundary-Layer Model of a Parallel-Plate Electrochemical Reactor for the Destruction of Nitrates and Nitrites in Alkaline Waste Solutions
}

\author{
Shailesh Prasad \\ University of South Carolina - Columbia \\ John W. Weidner \\ University of South Carolina - Columbia, weidner@engr.sc.edu \\ Andrew E. Farell \\ University of South Carolina - Columbia
}

Follow this and additional works at: https://scholarcommons.sc.edu/eche_facpub

Part of the Chemical Engineering Commons

\section{Publication Info}

Journal of the Electrochemical Society, 1995, pages 3815-3824.

(c) The Electrochemical Society, Inc. 1995. All rights reserved. Except as provided under U.S. copyright law, this work may not be reproduced, resold, distributed, or modified without the express permission of The Electrochemical Society (ECS). The archival version of this work was published in the Journal of the Electrochemical Society. http://www.electrochem.org/

Publisher's link: http://dx.doi.org/10.1149/1.2048419

DOI: $10.1149 / 1.2048419$

This Article is brought to you by the Chemical Engineering, Department of at Scholar Commons. It has been accepted for inclusion in Faculty Publications by an authorized administrator of Scholar Commons. For more information, please contact digres@mailbox.sc.edu. 


$$
Q=\ln \frac{i}{\exp \left(\frac{\alpha_{\mathrm{a}}+\alpha_{\mathrm{c}}}{R T} F \eta\right)-1}=\ln i_{\mathrm{o}}-\frac{\alpha_{\mathrm{c}} F}{R T} \eta
$$

so that a plot of $Q$ vs. $\eta$ yields a straight line with the intercept of $\ln \left(i_{o}\right)$. This plot is the so-called Allen-Hickling plot. This procedure has been used extensively to determine the exchange current density from potential step data.

The potential step data were collected with positive voltage feedback so that the voltage loss due to electrolyte resistance was compensated properly. The double-layer charging current is significant only in the initial time period. The kinetic current was obtained by square root extrapolation of the current between 0.6 and $1.0 \mathrm{~ms}$ to time zero. At least three measurements were taken at each potential. Sufficient time was allowed between measurements (usually $15 \mathrm{~min}$ ). The activation polarization curve for the high-Btu gas is shown in Fig. 3. The corresponding Allen-Hickling plot is presented in Fig. 4. The exchange current density calculated according to the above procedure is $1.49 \mathrm{~mA} / \mathrm{cm}^{2}$, which is more than an order of magnitude lower than that of copper $\left(26.3 \mathrm{~mA} / \mathrm{cm}^{2}\right)$ or nickel $\left(48.3 \mathrm{~mA} / \mathrm{cm}^{2}\right)$. The electrocatalytic activity of lithium ferrite is significantly lower than that of nickel or copper. The Allen-Hickling plots for medium and low-Btu gases are shown in Fig. 5 and 6 . A complete comparison of the three materials is listed in Table II.

\section{Summary}

An experimental approach was conducted to study the electrochemical properties of lithium ferrite as an alternative anode material in MCFC. Some unique characteristics were observed: ( $i$ ) the open-circuit potential was shifted in the positive direction for lithium ferrite. The measured OCP is a mixed potential; (ii) the steady state current is about $60 \%$ lower than that of nickel under the same conditions; (iii) two waves were found in the cyclic voltammograms: the first wave is attributed to hydrogen oxidation and the second wave is related to oxidation of $\mathrm{Fe}^{2+}$ to $\mathrm{Fe}^{3+}$ in the structure; $(i v)$ the exchange current density of hydrogen oxidation on lithium ferrite is an order of magnitude lower than that on copper or nickel; $(v)$ kinetically speaking, lithium ferrite is not a favorable anode material, despite its having better sulfur tolerance and sintering resistance than nickel.

\section{Acknowledgments}

This work was initiated under a Grant (DE-AC2188MC25026) from the U.S. Department of Energy. The experimental work was conducted at Institute of Gas Technology (Chicago, IL). Help from Dr. J. Y. Chu of Argonne National Laboratory (Argonne, IL) to prepare the electrodes was appreciated.

Manuscript submitted Feb. 13, 1995; revised manuscript received July 3, 1995.

\section{REFERENCES}

1. R. J. Remick, Final Report DOE/MC/20212-2039, (May 1986).

2. R. J. Remick, T. L. Osif, and M. G. Lawson, Final Report DOE/MC (1988).

3. R. D. Pierce, J. L. Smith, and G. H. Kucera, Progress in Batteries and Solar Cells, 6, 159 (1987).

4. W. M. Vogel and C. D. Iacovangelo, This Journal, 124, 1305 (1977)

5. S. H. Lu and J. R. Selman, ibid., 131, 2827 (1984).

\title{
A Boundary-Layer Model of a Parallel-Plate Electrochemical Reactor for the Destruction of Nitrates and Nitrites in Alkaline Waste Solutions
}

\author{
Shailesh Prasad, John W. Weidner," and Andrew E. Farell \\ Department of Chemical Engineering, University of South Carolina, Columbia, South Carolina 29208, USA
}

\section{ABSTRACT}

Electrochemical processes appear to be attractive for treating low level nuclear wastes. The development of a simple divided electrochemical-cell model operating in a batch mode, used for the reduction of nitrates and nitrites from nuclear wastes, is presented. This model, based on a boundary-layer approach, is simple and yet encompasses the key features of a previously developed distributed-parameter model that includes diffusion, migration, and convection as the flux components. Because it dramatically reduces computation time, this boundary-layer model is well suited for use in a complex interactive flowsheet model and for optimization studies. The boundary-layer model is used to predict partial current densities, reservoir concentrations, and off-gas compositions as a function of time. Good agreement between simulated and experimental data (i.e., nitrate and nitrite concentrations and off-gas compositions) is observed over the course of a batch run. In addition, a comparison with a rigorous distributed-parameter model is made to illustrate the accuracy and robustness of this model. The results of selected case studies are shown, and a preliminary batch optimization is carried out to show how the model can be used to maximize the destruction of nitrates and nitrites.

\section{Introduction}

Treatment of radioactive wastes from the production of nuclear materials is an area of widespread attention. At the Savannah River Site (SRS) in Aiken, SC, approximately 34 million gallons per year of aqueous radioactive waste resulting from production of nuclear materials is stored in large underground tanks. The Defense Waste Processing Facility (DWPF) at SRS is designed to separate the high level radioactive species from the waste and immobilize

* Electrochemical Society Active Member. them in a borosilicate glass wasteform. The resulting large volume (an accumulation of about 150 million gallons) of low level radioactive waste obtained after radioactive decontamination contains hazardous species in the form of nitrates, nitrites, heavy metals, and long-lived radionuclides. Electrochemical reduction is applicable for treating this highly concentrated waste and has the added ability for controlling the reaction selectivity by controlling the applied current. ${ }^{1,2}$

A flowsheet ${ }^{1}$ of the electrochemical process for treating the decontaminated waste is shown in Fig. 1. The process destroys the hazardous species, reduces the waste volume 
High-level wastes

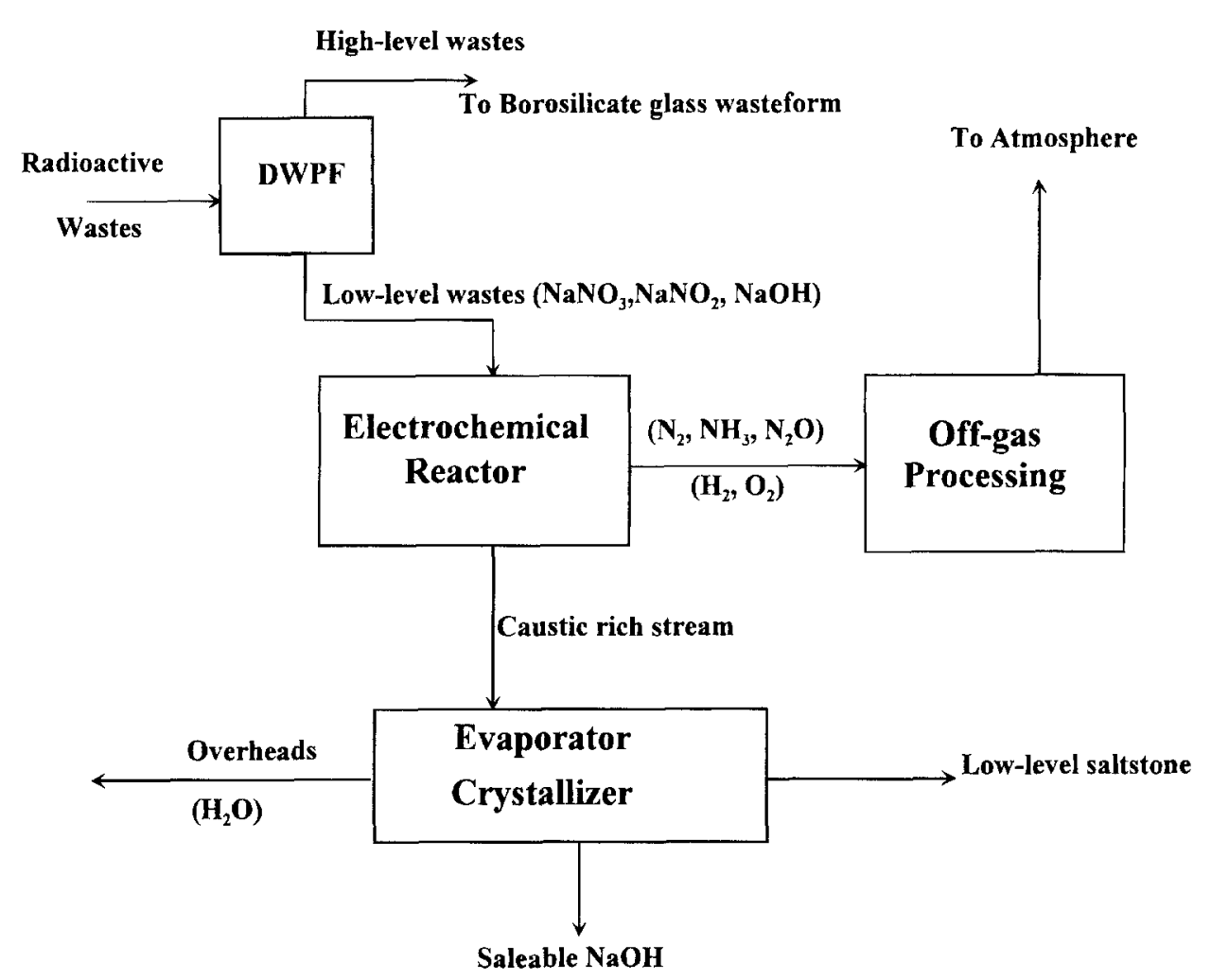

Fig. 1. Process flowsheet for the electrochemical treatment of liquid radioactive wastes.

requiring permanent storage, and reduces the corrosiveness of the waste. The average composition of the decontaminated waste is tabulated in Table I. The waste is fed to the parallel-plate electrochemical reactor as the catholyte where the nitrates and nitrites are reduced to ammonia, nitrogen, and nitrous oxide according to the following reactions $^{1-3}$ (standard hydrogen electrode $=\mathrm{SHE}$ )

$$
\begin{array}{cc} 
& U^{\theta}(\mathrm{V} v s . \mathrm{SHE}) \\
\mathrm{NO}_{3}^{-}+\mathrm{H}_{2} \mathrm{O}_{(\mathrm{l})}+2 e^{-} \rightarrow \mathrm{NO}_{2}^{-}+2 \mathrm{OH}^{-} & 0.01 \\
\mathrm{NO}_{2}^{-}+5 \mathrm{H}_{2} \mathrm{O}_{(\mathrm{ll})}+6 e^{-} \rightarrow \mathrm{NH}_{3(\mathrm{~g})}+7 \mathrm{OH}^{-} & -0.165 \\
2 \mathrm{NO}_{2}^{-}+4 \mathrm{H}_{2} \mathrm{O}_{(1)}+6 e^{-} \rightarrow \mathrm{N}_{2(\mathrm{~g})}+8 \mathrm{OH}^{-} & 0.406 \\
2 \mathrm{NO}_{2}^{-}+3 \mathrm{H}_{2} \mathrm{O}_{(\mathrm{l})}+4 e^{-} \rightarrow \mathrm{N}_{2} \mathrm{O}_{(\mathrm{g})}+6 \mathrm{OH}^{-} & 0.15
\end{array}
$$

The product gases are separated from the liquid waste and sent to an off-gas processing unit where the toxic gases (mainly ammonia) are removed, and the nitrogen is vented to the atmosphere. The catholyte leaves the electrochemical reactor following $95 \%$ reduction of nitrates and nitrites and is sent to an evaporator/crystallizer where three streams are produced: $(i)$ crystals containing $\mathrm{NaOH}$ and unreacted nitrates and nitrites are formed in the crystallizer by cooling the evaporator underflow. The crystals are later dissolved and sent to a low level waste disposal where the waste is incorporated into a cement matrix and placed in a near surface vault; (ii) concentrated caustic solution is withdrawn as a value-added product from the crystallizer;

Table I. Composition of the decontaminated salt-solution simulant.

\begin{tabular}{cl}
\hline Component & Concentration $(M)$ \\
\hline $\mathrm{NaNO}_{3}$ & 1.95 \\
$\mathrm{NaNO}_{2}$ & 0.6 \\
$\mathrm{NaOH}$ & 1.33 \\
$\mathrm{NaAl}(\mathrm{OH})_{4}$ & 0.31 \\
$\mathrm{Na}_{2} \mathrm{SO}_{4}$ & 0.14 \\
$\mathrm{Na}_{2} \mathrm{CO}_{3}$ & 0.16 \\
$\mathrm{NaCl}$ & 0.022 \\
$\mathrm{NaF}$ & 0.015 \\
$\mathrm{Na}_{2} \mathrm{CrO}_{4}$ & 0.0033 \\
$\mathrm{Na}_{3} \mathrm{PO}_{4}$ & 0.0085 \\
$\mathrm{Na}_{2} \mathrm{SiO}_{3}$ & 0.0038 \\
$\mathrm{NaB}\left(\mathrm{C}_{6} \mathrm{H}_{5}\right)_{4}$ & 0.0026
\end{tabular}

and (iii) evaporator overheads are transferred to the Effluent Treatment Facility for treatment prior to release to groundwater outfall.

Although the flowsheet depicts the destruction of hazardous species as a continuous operation, in reality each unit operation is performed in a batchwise manner. The arrows in the flow diagram in Fig. 1 simply indicate the direction of material transport. For example, Fig. 2 shows the unit operation for the electrochemical destruction of nitrates and nitrites. Since the single-pass conversion is low (necessary to prevent accumulation of gas within the electrochemical cell), recirculation in a batchwise fashion is required to achieve $95 \%$ destruction of nitrates and nitrites. Each pass through the cell is followed by flashing of the gaseous products in the recirculation tank. Although the electrochemical reactor operates in a batch mode, optimal equipment design and proper process scheduling require a comprehensive analysis of the combined flowsheet. Recycle streams add additional interaction between the unit operations. For these reasons, optimization of the process flowsheet requires a dynamic flowsheet model.

Our objective is to develop a computationally efficient electrochemical reactor model. Computational efficiency is a key requirement of this work since the reactor and the recirculation tank are to be incorporated into a process flowsheet model in future optimization studies. This efficiency, however, must be obtained while maintaining the key features found in the previous reactor model ${ }^{4}:$ (i) multiple reaction pathways for nitrate/nitrite reduction of which reactions 1 and 3 are most desirable; (ii) hydrogen evolution as a competing reaction; (iii) transport of nitrates and nitrites across the separator due to migration and diffusion; (iv) transport limitations of nitrates and nitrites to the electrode surface caused by migration and diffusion; and $(v)$ voltage losses due to kinetic and ohmic resistances.

The competing hydrogen evolution reaction mentioned in item (ii) above is due to the reduction of water

$$
2 \mathrm{H}_{2} \mathrm{O}_{(2)}+2 e^{-} \rightarrow \mathrm{H}_{2(\mathrm{~g})}+2 \mathrm{OH}^{-} \quad \frac{U^{\theta}(\mathrm{V} v s . \mathrm{SHE})}{-0.828}
$$

Although the standard potential for water reduction is significantly more negative than reactions 1 through 4 , the slow reaction kinetics for nitrate and nitrite reduction can cause a significant portion of the applied current to be con- 


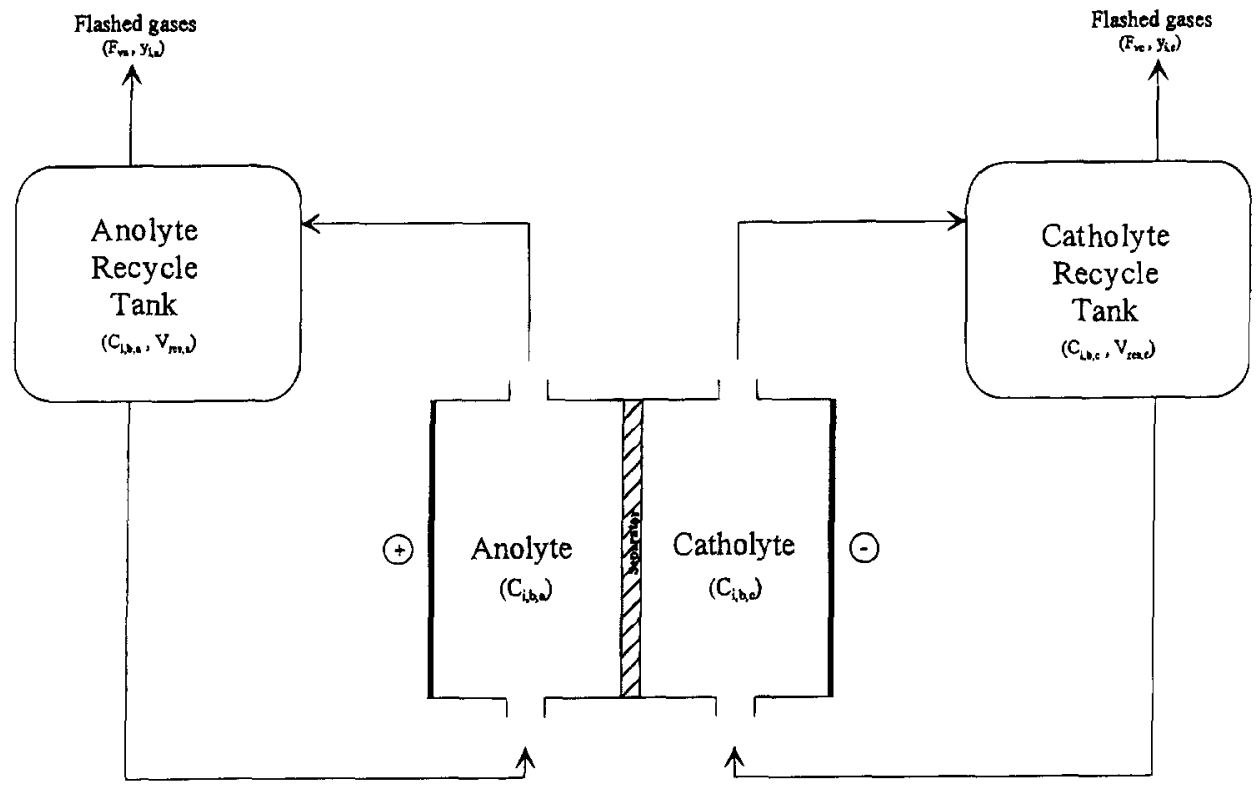

Fig. 2. Divided cell in batch mode.

sumed by reaction $5 .^{4}$ This undesirable situation is particularly severe if the cell is operated at currents above the limiting currents of the desired reactions, a situation which may be difficult to avoid near the end of a batch run when concentrations of nitrates and nitrites are low.

Some parallel-plate electrochemical-cell models exist in the literature. Parrish and Newman ${ }^{5}$ presented a one-dimensional, distributed-parameter model to analyze the current distribution of a single reaction in a channel-flow cell where concentration gradients in the flow direction were ignored and anode and cathode boundary layers did not interact. Sakellaropolous and Francis ${ }^{6}$ added multiple reactions, and they analyzed product selectivity and yield for a system of two parallel electrocatalytic reductions. Edwards and Newman ${ }^{7}$ extended these works by modeling a thin-gap channel flow cell with multiple reactions and interacting anode and cathode boundary layers.

White et $a l .{ }^{8}$ presented a two-dimensional, distributedparameter model of an undivided electrochemical cell which was used to model multiple reactions at the cathode. This model described two series reactions for the electrowinning of copper from a chloride solution and used Newman's ${ }^{9}$ BAND algorithm to predict product selectivity along with current and energy efficiencies. In addition, their study presented an analysis of the dependence of current efficiency on aspect ratio and Péclet number.

The above models ${ }^{5-8}$ form the basis of the work by Coleman et $a l .{ }^{4}$ in which they developed a two-dimensional, distributed-parameter model of a divided cell that describes the destruction of nitrates and nitrites in alkaline waste solutions. The model assumes laminar flow and includes the effects of the separator, ionic migration, electrode resistances, multiple reactions, and cell gap. Also, all the time-dependence is incorporated into the recirculation tank since the volume of the tank is much greater than that of the cell. The governing differential equations are transformed into a set of coupled algebraic equations using a finite-difference approximation for the derivatives. The solution procedure uses the BAND algorithm to solve for these transformed steady-state continuity and electroneutrality equations in the catholyte and anolyte regions of the electrochemical cell, and an implicit time-stepping technique is used to account for the dynamics of the recirculation tank. The model is used to predict the partial current densities, concentration profiles, and the potential profile for a given set of operating conditions. This model is, however, computationally intensive for optimization studies and for use in the flowsheet simulation of the entire treatment process.

Previous investigations have devised solution procedures and strategies to reduce computer time using a boundary- layer approach while maintaining the key features of the distributed-parameter models. The model presented by White et $a l .{ }^{8}$ was further modified by Mader et al. ${ }^{10}$ to reduce the computational time substantially. The axial concentration gradient was assumed to be linear and equated to the ratio of the change in concentration (from inlet to outlet) to the reactor length. This changed the model from two-dimensional to one-dimensional (radial direction). Caban and Chapman ${ }^{11}$ presented a model which focused mainly on simpler techniques for the solution of ordinary differential equations. They used orthogonal collocation with new approximating functions to solve for transport in the boundary layer (with reaction term included), which gave them concentration profiles and current densities that agree well with rigorous calculations. Lee and Selman ${ }^{12}$ presented a model similar to that of Caban and Chapman, ${ }^{11}$ but they added the effects of separator and electrode resistances. The model developed was for a two-dimensional parallel-plate flow reactor, using the $\mathrm{Zn} / \mathrm{Br}_{2}$ system as an example. Smeltzer and Fedkiw ${ }^{13}$ used an innovative technique to analyze the effect of periodic cell voltage control ${ }^{14}$ on the reduction of nitrobenzene. To model the reactor, they used the analytic solution to Laplace's equation in conjunction with an analytic solution to the transient diffusion equation within the stagnant boundary layer at the electrode surface.

The stagnant boundary-layer approach is extended here to include the transport of ions via migration as well as diffusion across the boundary layer. Coleman et al. ${ }^{4}$ showed that the migrational component of the flux can dominate when the current resulting from the hydrogen evolution reaction is significant. Migration can cause the repulsion of the negatively charged nitrate and nitrite ions away from the cathode surface, thus significantly reducing the partial current densities of the desired reactions.

Since the destruction of nitrates and nitrites involves a combination of an electrochemical reactor and recirculation tanks in total recycle (Fig. 2), bulk concentrations of reactants and products must be tracked as a function of time. In addition to the work by Coleman et al.. ${ }^{4}$ several time-dependent models for the parallel-plate electrochemical cell with recirculation have been developed. ${ }^{15-17}$ However, these models do not simultaneously consider the effect of potential, ionic migration, electrode kinetics, and flashing of gases produced in the reactor or include time-dependence in the reactor and the recirculation tank.

A boundary-layer model is presented here along with results from a few independent case studies (including a comparison between model predictions and experimental data) and a brief discussion of the optimal operation of the cell. The boundary-layer model has been designed to be used 
mainly as a module in the flowsheet and for optimization studies. The distributed-parameter model, ${ }^{4}$ though precise, takes a significant amount of computation time to run. A comparison between the results from the boundary-layer model and the distributed-parameter model is presented, which shows that the boundary-layer model yields accurate results more efficiently.

The equations for the boundary-layer model are written in SPEEDUP ${ }^{\mathrm{TM}}$, a Aspentech's dynamic flowsheet simulator. Since the process stream is nonideal (due to the presence of polar species like water and many gases), the use of rigorous thermodynamics is desirable. Using SPEEDUP as the programming environment further facilitates the use of rigorous thermodynamics. The vapor-liquid-equilibrium (VLE) data are obtained by connecting the program to Properties Plus, ${ }^{a}$ which is Aspentech's physical properties database.

\section{Model Development}

Figure 2 shows the batch electrochemical system. The divided cell is a parallel-plate electrochemical reactor with a separator between the cathode and the anode. Previous researchers ${ }^{1-3,18}$ have reported significant oxidation of nitrites to nitrates and a high possibility of $\mathrm{NH}_{3}$ and $\mathrm{O}_{2}$ forming an explosive mixture in an undivided cell. The use of a separator minimizes oxidation of the nitrites to nitrates at the anode and also prevents free mixing of $\mathrm{NH}_{3}$ and $\mathrm{O}_{2}$. The purpose of the recirculation tank is to process a large system inventory and to enable the gases trapped in the stream to flash. Table II gives the simulated feed composition of the anolyte and catholyte at the start of the batch run.

Model assumptions.-The following assumptions are used to develop the batch electrochemical reactor model.

1. The dynamics of the reactor are fast relative to recirculation tank dynamics.

2. No homogeneous chemical reactions occur in the reactor.

3. Dilute solution theory applies.

4. The Nernst - Einstein equation $\left(u_{i}=D_{1} /(\Re T)\right.$ applies.

5. The Butler-Volmer equation can be used to describe the reactions at the electrode surface.

6. Isothermal conditions exist.

7. The gases produced at the electrode surface stay in solution in the reactor and are flashed on entering the recirculation tank.

8. The solution conductivity is uniform in each of the anolyte, catholyte, and separator regions.

9. Perfect mixing is achieved in the recirculation tank.

10. The physical transport parameters are constant.

11. The density of the process stream remains constant.

12. The concentration of gases in the anolyte stream is low.

Assumption 1 is valid because the volume of the reactor is small compared to the recirculation tank. Assumptions 2 through 6 are common to most parallel-plate electrochemical reactor models. Assumption 7 holds because the amount of gas produced at each pass is always below saturation limits, because the conversion per pass is low. Assumption 8 arises from the fact that the conductivity is a function of the sum of the species concentrations and remains almost unchanged (since all the species in the simulated waste carry unit charges, and electroneutrality is maintained).

a These products are available through Aspen Technology, Inc., Ten Canal Park, Cambridge, MA 02141, USA.

Table II. Feed composition used in the simulations. The values in parentheses were used in the constant-current batch run shown in Fig. 5 .

\begin{tabular}{ccc}
\hline Species & $\begin{array}{c}\text { Initial catholyte } \\
\text { composition } \\
(M)\end{array}$ & $\begin{array}{c}\text { Initial anolyte } \\
\text { composition } \\
(M)\end{array}$ \\
\hline $\mathrm{NO}_{3}^{-}$ & $1.95(1.82)$ & $1.95 \times 10^{-3}$ \\
$\mathrm{NO}_{2}^{-}$ & $0.6(0.56)$ & $0.6 \times 10^{-4}$ \\
$\mathrm{OH}^{-}$ & 1.33 & 3.8797 \\
$\mathrm{Na}^{+}$ & $3.88(3.71)$ & 3.88
\end{tabular}

Assumptions 9 through 11 are common in continuous stirred tank reactor (CSTR) modeling. Assumption 12 is based on results from preliminary studies. ${ }^{3,18}$

Governing equations for a single pass. - The function of the electrochemical reactor is to destroy the nitrates and nitrites. This is achieved by reducing them to gases such as nitrogen, ammonia, and nitrous oxide. Reactions 1 through 5 occur at the cathode, and the following oxygen evolution reaction is the main reaction at the anode

$$
4 \mathrm{OH}^{-} \rightarrow \mathrm{O}_{2(\mathrm{~g})}+2 \mathrm{H}_{2} \mathrm{O}_{(\mathrm{l})}+4 e^{-} \quad \frac{U^{\theta}(\mathrm{V} v s . \mathrm{SHE})}{0.401}
$$

Due to assumption 12 , reactions 2 through 5 are ignored at the anode but reaction 1 is considered by including the transport of nitrites through the separator. The reactions can be written in the following general format ${ }^{9}$

$$
\sum_{i} s_{\mathrm{ij}} M_{\mathrm{i}}^{z_{\mathrm{i}}} \rightarrow n_{\mathrm{j}} e
$$

In this format, the stoichiometric coefficient, $s_{\mathrm{ij}}$, is positive for products and negative for reactants when the reaction is written as a reduction.

The Butler-Volmer rate expression is used to relate the partial current $\left(i_{j}\right)$ associated with reaction $j$ to the surface concentration $\left(C_{i, s}\right)$ of species $i$ and the overpotential $\left(\eta_{\mathrm{j}}\right)$ for reaction $j$. The Butler-Volmer rate expression relative to reference conditions can be written for the catholyte as ${ }^{19}$

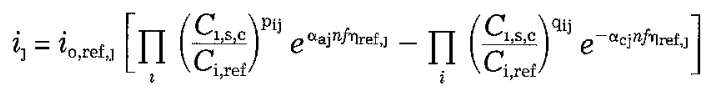

where

$$
\begin{gathered}
\eta_{\mathrm{ref}, \mathrm{l}}=V_{\mathrm{c}}-\phi_{\mathrm{c}}-U_{\mathrm{ref}, \mathrm{j}} \text { for reactions at the cathode } \\
\eta_{\mathrm{ref}, \mathrm{j}}=V_{\mathrm{a}}-\phi_{\mathrm{a}}-U_{\mathrm{ref}, \mathrm{j}} \text { for reactions at the anode } \\
U_{\mathrm{ref}, \mathrm{j}}=U_{\mathrm{j}}^{\theta}-\frac{1}{n_{\mathrm{j}} f} \sum_{i} \ln \left(\frac{1}{C_{\mathrm{i}, \mathrm{ref}}}\right)
\end{gathered}
$$

and

$$
p_{\mathrm{ij}}=s_{\mathrm{i} j}, \quad q_{\mathrm{ij}}=0 \text { if } s_{\mathrm{ij}}>0 ; \quad p_{\mathrm{ij}}=0, \quad q_{\mathrm{ij}}=-s_{\mathrm{ij}} \text { if } s_{\mathrm{ij}}<0
$$

The expression relating $\phi_{\mathrm{c}}$ and $\phi_{\mathrm{a}}$ based on assumption 8 is

$$
\phi_{\mathrm{a}}=\phi_{\mathrm{c}}+i_{\mathrm{t}} A R_{\text {cell }}
$$

where

$$
R_{\text {cell }}=\frac{1}{A}\left(\frac{S_{\mathrm{a}}}{\kappa_{\mathrm{a}}}+\frac{S_{s} N_{\mathrm{m}}}{\kappa_{\mathrm{s}}}+\frac{S_{\mathrm{c}}}{\kappa_{\mathrm{c}}}\right)
$$

where

$$
\kappa_{\mathrm{c}}=\frac{F^{2}}{\Re T} \sum_{i} z_{1}^{2} D_{\mathrm{i}} C_{\mathrm{i}, \mathrm{b}, \mathrm{e}}
$$

and

$$
\kappa_{\mathrm{a}}=\frac{F^{2}}{\Re T} \sum_{i} z_{\mathrm{i}}^{2} D_{\mathrm{i}} C_{\mathrm{i}, \mathrm{b}, \mathrm{a}}
$$

In Eq. 8, the term $C_{i, s . c}$ is unknown. Therefore a relation between this quantity and other system variables must be developed. Both diffusion and migration contribute to the flux of species i through the diffusion layer and therefore the flux is given by

$$
N_{1}=-D_{\mathrm{i}} \frac{d C_{\mathrm{i}}}{d x}-\frac{z_{\mathrm{i}} D_{\mathrm{i}} F}{\mathfrak{R} T} C_{\mathrm{i}} \frac{d \phi}{d x}
$$

Since the potential drop across the catholyte is constant (due to assumption 8), Ohm's law allows the $(d \phi / d x)$ term to be replaced by $\left(-i_{t} / \kappa_{\mathrm{c}}\right)$ to give

$$
N_{\mathrm{i}}=-D_{\mathrm{1}} \frac{d C_{1}}{d x}+\frac{z_{i} D_{\mathrm{i}} F}{\Re T} \frac{i_{\mathrm{t}}}{\kappa_{\mathrm{c}}} C_{1}
$$

Further, the flux of species $i$ in the boundary layer is assumed to be constant and related to the total current density $\left(i_{t}\right)$ as follows

$$
N_{1}=-\sum_{j} \frac{s_{\mathrm{i}} i_{\mathrm{i}}}{n_{\mathrm{j}} F}
$$


Substituting Eq. 13 into Eq. 12 and integrating across the boundary layer from $x=0$ to $x=\delta_{i}$ gives the surface concentration for species $i$ as

$$
C_{\mathrm{i}, \mathrm{s}, \mathrm{c}}=\left(\frac{N_{\mathrm{i}}}{D_{\mathrm{i}} \gamma_{\mathrm{i}}}\right)+\left(C_{\mathrm{i}, \mathrm{b}, \mathrm{c}}-\frac{N_{\mathrm{i}}}{D_{\mathrm{i}} \gamma_{\mathrm{l}}}\right) e^{\gamma_{\mathrm{i}} \hat{\mathrm{i}}_{\mathrm{i}}}
$$

where

and

$$
\gamma_{\mathrm{i}}=\frac{\mathrm{z}_{\mathrm{i}} F i_{\mathrm{t}}}{\mathfrak{R T} \kappa_{\mathrm{c}}}
$$

$$
i_{\mathrm{t}}=\sum_{j} i_{\mathrm{j}}
$$

The boundary-layer thickness, $\delta_{1}$, is related to the masstransfer coefficient (which in turn is related to the Nusselt number) as follows

$$
\delta_{\mathrm{i}}=\frac{D_{\mathrm{i}}}{k_{\mathrm{m}, \mathrm{i}}}=\frac{2 S}{\mathrm{Nu}}
$$

Newman ${ }^{9}$ gives an expression for the average Nusselt number for flow between two planar electrodes which is accurate for long electrodes (i.e., fully developed flow)

$$
\mathrm{Nu}_{\mathrm{i}}=1.8488\left(\frac{\operatorname{ReSc}_{1} d_{\mathrm{e}}}{L}\right)^{1 / 3}-0.4
$$

in which

$$
\operatorname{Re}=\frac{d_{\mathrm{e}} v}{v}
$$

and

$$
\mathrm{Sc}_{1}=\frac{\nu}{D_{i}}
$$

The -0.4 term on the right side of Eq. 17 is included to account for a fully developed boundary layer in a long channel. Equations analogous to 8 through 14 can be written for the anolyte boundary layer as well.

Butler-Volmer equations ( $\mathrm{Eq}$. 8) for each reaction are solved simultaneously along with Eq. 10 and a set of equations governing the surface concentrations (Eq. 14) to evaluate the individual current densities. Coleman et al. ${ }^{4}$ use Eq. 8 through 12 along with a convective term in the direction of flow to evaluate the current densities. This approach requires coupled partial differential equations to be solved throughout the cell gap using a numerical procedure. The boundary-layer model assumes that all the concentration gradients lie within a region near the electrode surface. Hence, once the boundary-layer thickness $\left(\delta_{1}\right)$ is estimated for a particular flow configuration, the current densities can be evaluated. Therefore, the analytic solution for the surface concentration (Eq. 14) is applicable for any flow system in which a boundary-layer thickness can be estimated [e.g., rotating-disk electrode (RDE), parallel plate under turbulent flow conditions]. The results presented here are for a laminar system. For a turbulent flow system, the estimated boundary-layer thickness decreases, and therefore reactions 1 to 4 are enhanced. For this reason, the boundary-layer model is versatile and can be modified easily to handle any flow system or cell configuration. The distributed-parameter model cannot be modified as easily since the velocity profile in the catholyte/anolyte governing equations must be changed.

Governing equations for a batch run. - The batch system consists of the electrochemical reactor and two recirculation tanks. The main purpose of the recirculation tanks is to allow processing of a large system inventory. It also aids in the flashing of gases trapped in the process streams. Due to assumption 1, which states that the dynamics of the reactor are negligible, the species molar balance in the catholyte portion of the batch cell (Fig. 2) is written as

$$
\frac{d\left(V_{\mathrm{res}, \mathrm{c}} C_{\mathrm{i}, \mathrm{b}, \mathrm{c}}\right)}{d t}=-\sum_{j .} \frac{s_{\mathrm{ij}} i_{\mathrm{j}} A}{n_{\mathrm{j}} F}-A N_{\mathrm{i}, \mathrm{s}}-F_{\mathrm{vc}} y_{\mathrm{i}, \mathrm{c}}
$$

where $N_{\mathrm{iss}}$ represents the net flux through the separator. The vapor flow rate $\left(F_{\mathrm{vc}}\right)$ and mole-fractions $\left(y_{\mathrm{i} . \mathrm{c}}\right)$ are evalu-
Table Ill. Kinetic parameters, physical parameters, and operating conditions used in the simulations. Values in parentheses were used in the constant-current batch run shown in Fig. 5 .

Exchange current densities $\left(\mathrm{A} / \mathrm{cm}^{2}\right)^{4}$

$\begin{array}{ll}\text { Reaction 1 (cathode) } & 8.0 \times 10^{-10} \\ \text { Reaction 2 } & 8.5 \times 10^{-11} \\ \text { Reaction 3 } & 3.0 \times 10^{-15} \\ \text { Reaction 4 } & 1.5 \times 10^{-13} \\ \text { Reaction 5 } & 3.0 \times 10^{-6} \\ \text { Reaction 6 } & 1.9 \times 10^{-11} \\ \text { Reaction 1 (anode) } & 1.0 \times 10^{-15} \\ \left.\text { sion coefficients (cm }{ }^{2} / \mathrm{s}\right): & \\ \mathrm{Na}^{+} & 1.334 \times 10^{-5} \\ \mathrm{OH}^{-} & 5.26 \times 10^{-5} \\ \mathrm{NO}_{3}^{-} & 1.902 \times 10^{-5} \\ \mathrm{NO}_{2}^{-} & 1.902 \times 10^{-5} \\ \mathrm{~N}_{2} & 1.9 \\ \mathrm{NH}_{3} & 2.168 \times 10^{-5} \\ \mathrm{~N}_{2} \mathrm{O} & 1.801 \times 10^{-5} \\ \mathrm{O}_{2} & 2.151 \times 10^{-5} \\ \mathrm{H}_{2} & 2.322 \times 10^{-5} \\ \text { Catholyte volume } & 700 \mathrm{~cm}^{3} \\ \text { Anolyte volume } & 7000 \mathrm{~cm} \\ \text { Cell length } & 10.0 \mathrm{~cm} \\ \text { Cell width } & 10.0 \mathrm{~cm} \\ \text { Electrode gap } & 1.25 \mathrm{~cm} \\ \text { Avg axial fluid velocity } & 10.5 \mathrm{~cm} / \mathrm{s}(13.5 \mathrm{~cm} / \mathrm{s}) \\ \text { Separator thickness } & 0.05 \mathrm{~cm} \\ \text { MacMullin number } & 5.0 \\ \text { Volumetric flow rate } & 63.0 \mathrm{~cm} / \mathrm{s}(81 \mathrm{~cm} / \mathrm{s}) \\ & \end{array}$

ated using the "flash" routine in the SPEEDUP library. The "flash" routine solves for the component balances and the enthalpy balance by using the necessary vapor-liquidequilibrium relationships and volume constraints. The input parameters to the "flash" routine are the inlet flow rate, inlet composition, pressure, and temperature of the flash tank. The physical properties are obtained using Properties Plus. A similar procedure can be written for the anolyte portion.

An equation analogous to Eq. 12 can be written for the flux of species $i$ across the separator

$$
N_{\mathrm{i}, \mathrm{s}}=-D_{\mathrm{i}, \mathrm{e}} \frac{d C_{\mathrm{i}}}{d x}+\frac{z_{\mathrm{i}} D_{\mathrm{i}, \mathrm{e}} F}{\Re T} \frac{i_{\mathrm{t}}}{\kappa_{\mathrm{s}}} C_{1}
$$

Integrating Eq. 19 by using the known concentrations on both sides of the separator and rearranging gives

$$
N_{i, s}=\left[C_{i, b, a}-C_{i, b, c} e^{\gamma_{i, s} \delta_{s}}\right]\left[\frac{D_{i, e} \gamma_{1, s}}{1-e^{\gamma_{i, s} \delta_{s}}}\right]
$$

where

$$
D_{\mathrm{i}, \mathrm{e}}=\frac{D_{1}}{\mathrm{~N}_{\mathrm{m}}} \quad \text { and } \quad \gamma_{\mathrm{i}, \mathrm{s}}=\frac{z_{\mathrm{i}} F i_{\mathrm{t}}}{\mathfrak{R} T \kappa_{\mathrm{s}}}
$$

and

$$
\kappa_{\mathrm{s}} \frac{F^{2}}{2 \Re T} \sum_{\mathrm{i}} z_{\mathrm{i}}^{2} D_{\mathrm{l}, \mathrm{e}}\left(C_{\mathrm{i}, \mathrm{b}, \mathrm{c}}+C_{\mathrm{i}, \mathrm{b}, \mathrm{a}}\right) \mathrm{N}_{\mathrm{m}}
$$

The separator used here is permeable to all species. The effective diffusion coefficient and the conductivity are characterized by a MacMullin number, ${ }^{20} \mathrm{~N}_{\mathrm{m}}$, which is a function of the separator's porosity and tortuosity.

The boundary-layer model assumes that the gases produced remain in solution inside the electrochemical reactor. After passing through the reactor, a flash occurs in the recirculation tank. The SPEEDUP program is connected to Properties Plus so that the physical properties and VLE calculations can be determined accurately. Properties Plus uses the UNIFAC ${ }^{21}$ [UNIQUAC (universal quasi chemical) functional-group activity coefficients] approach to perform VLE calculations.

\section{Results and Discussion}

Results from a single-pass calculation and from batch runs are presented using the physical and kinetic parameters obtained by Coleman et al. ${ }^{4}$ (listed in Table III). The diffusion coefficients used for the ionic species were from limiting ionic conductivity data. ${ }^{9}$ Those for gases were esti- 


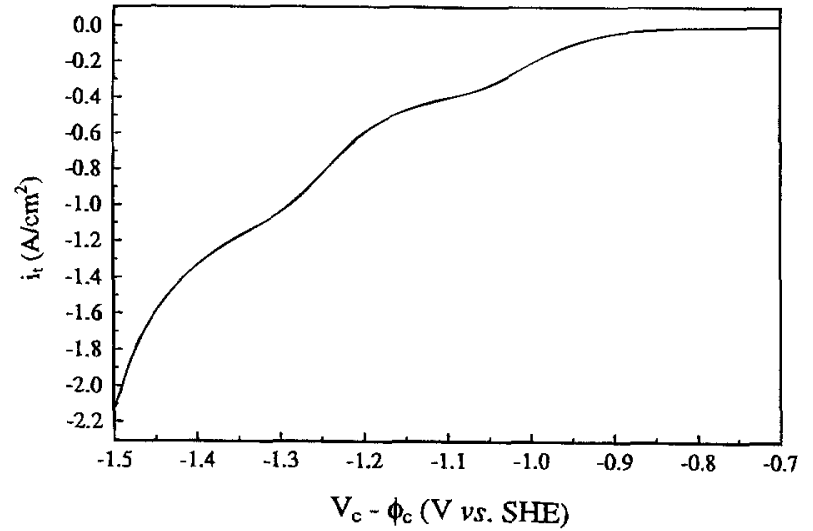

Fig. 3. Total current density $\left(i_{i}\right)$ as a function of the potential difference at the cathode vs. SHE $\left(V_{c}-\phi_{c}\right)$. The single-pass simulation is performed at the initial feed concentrations.

mated from the Wilke-Chang estimation method assuming that water is the solvent. The values for the exchange current densities were chosen to match the experimentally measured $^{3}$ nitrate and nitrite concentrations and off-gas compositions as a function of charge passed (as pointed out later in reference to Fig. 8 and 9). The validity of these parameters is demonstrated by comparison with experimental data from a batch run (see discussion under batch simulation results).

Single-pass simulation at the initial feed concentrations. - In a single pass, the system concentrations undergo a negligible change, and consequently the current-voltage relationships at the anode and cathode are unaffected by the transport across the separator and the dynamics of the flash tank. Therefore, the reaction currents at the cathode are isolated from those at the anode. In addition, the singlepass results are used to determine how accurately the boundary-layer model treats transport of ions to the electrode surface by comparing them with results from the distributed-parameter model. ${ }^{4}$ Single-pass studies also are performed at various times during a batch run to illustrate that an optimum current exists, and how this optimum changes during the run.

Figures 3 and 4 result from a single-pass simulation at the initial feed concentrations shown in Table II. A singlepass simulation is performed by solving Eq. 8, 10, and 14 using the boundary-layer approach where the thickness of the boundary layer is evaluated from Eq. 16 and 17. The abscissa on these curves is the potential difference of the

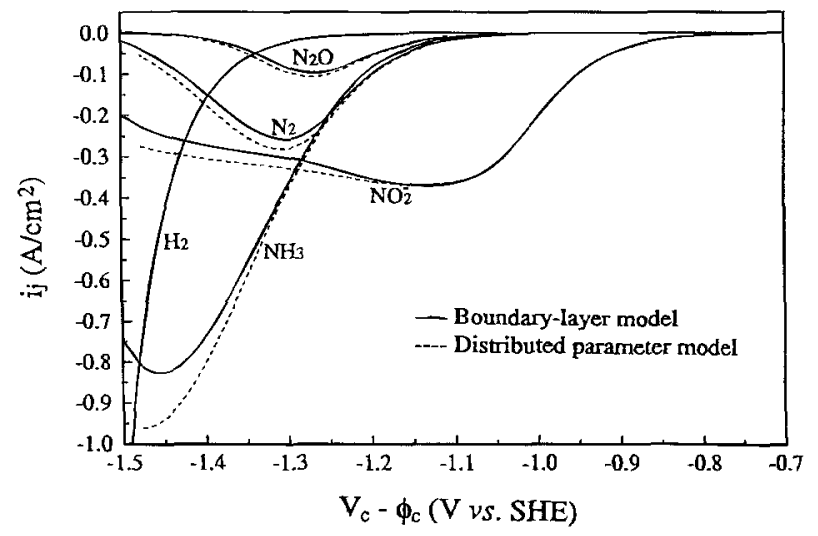

Fig. 4. Comparison of the cathodic current density curves between boundary-layer and distributed-parameter models. The single-pass simulation is performed at the initial/feed concentrations. The predictions match well for $\left(V_{c}-\phi_{c}\right)=-0.7$ to $-1.3 \mathrm{~V}$. Beyond $-1.33 \mathrm{~V}$, the assumption of a linear potential gradient in the boundary layer overestimates the migrational flux, and hence underestimates the reaction current. The labels denote the products from reactions 1 through 5 . cathode relative to an SHE. This potential difference relative to the thermodynamic reference potential of a particular reaction is the overpotential driving force for that reaction. Since the results from the boundary-layer model shown in these figures are not affected by the separator or the flash tank, they are applicable for an RDE, a parallelplate reactor, or any flow system in which a boundary layer is established. For example, the boundary-layer thickness for nitrate in Fig. 3 and 4 is $0.01645 \mathrm{~cm}$, which is equivalent to a rotation speed of $\sim 20 \mathrm{rpm}$ on an RDE.

In Fig. 3, negligible current is obtained at a potential difference less negative than $-0.7 \mathrm{~V}$ due to the slow kinetics of reactions 1 through 5 . As the potential difference becomes more negative, two current plateaus are observed at -1.1 and $-1.3 \mathrm{~V}$. This suggests that two reactions reach their limiting current before the water reduction reaction dominates at potential differences more negative than $-1.4 \mathrm{~V} v$ s. SHE. However, if the exchange current density for the water reaction is greater, or those for nitrate and nitrite reactions are less than those shown in Table III, these two plateaus are not visible. Therefore, little quantitative or even qualitative information can be obtained from an experiment that gives only the total current $v s$. the applied potential difference.

Figure 4 shows the current-voltage curve from Fig. 3 separated into the individual reactions. Analogous curves generated from the distributed-parameter model ${ }^{4}$ are shown (in dotted lines) for comparison. A thorough description of these curves is presented before analyzing the agreement or discrepancy between the two set of curves.

Considerable insight regarding the interactions of reactions 1 through 5 can be obtained by examining the individual reaction currents $v s$. the applied potential difference. At potential differences less negative than $-1.0 \mathrm{~V}$, the system is under activation control with only reaction 1 proceeding at an appreciable rate. At approximately $-1.1 \mathrm{~V}$, reactions 2 through 4 begin to contribute to the overall current, and reaction 1 becomes limited by the rate of diffusion of nitrate to the electrode surface. This corresponds to the first plateau seen in Fig. 3.

At potential differences more negative than $-1.1 \mathrm{~V} v s$. $\mathrm{SHE}$, reactions 2 through 4 begin to dominate, and the rate of reaction 1 decreases. This anomalous behavior is due to the migrational component in Eq. 12. As the total current increases, the potential gradient across the boundary layer increases in magnitude. Since the nitrate ion is negatively charged, it is forced away from the cathode causing the reaction rate to decrease. The nitrite ion is also forced away from the cathode, but the rates of reactions 2 through 4 do not begin to decrease immediately due to simultaneous production of nitrite through reaction 1 . The production of nitrite at the surface delays the onset of mass-transfer limitations. Therefore, the rates of reactions 2 through 4 continue to increase even though the rate of reaction 1 decreases due to migration. At potential differences more negative than $-1.45 \mathrm{~V} v s$. SHE, reaction 5 proceeds at a significant rate, and the reaction rate for reactions 2 through 4 decreases below the diffusion-limiting current. The peak in the $\mathrm{NH}_{3}$ partial current occurs at the largest cathodic overpotential since the order of reaction 2 (defined as the stoichiometric coefficient of $\mathrm{NO}_{2}^{-}$relative to the number of electrons) is much lower than that for reactions 3 and 4 . This relatively small dependence on the reactant (i.e., $\mathrm{NO}_{2}^{-}$) surface concentration causes the $\mathrm{NH}_{3}$ curve to keep rising, even though the $\mathrm{N}_{2}$ and $\mathrm{N}_{2} \mathrm{O}$ curves begin to decrease.

From a comparison viewpoint, it can be seen that excellent agreement is observed between the two models at the onset of mass-transfer limitations for reaction 1 , which demonstrates that transport to the electrode surface can be well characterized by a boundary-layer approximation. Some discrepancy between the two models is observed at higher currents since the distributed-parameter model predicts a slight parabolic potential profile in this region. The linear potential profile assumed in this model introduces a slight underprediction of the partial currents, but this dis- 


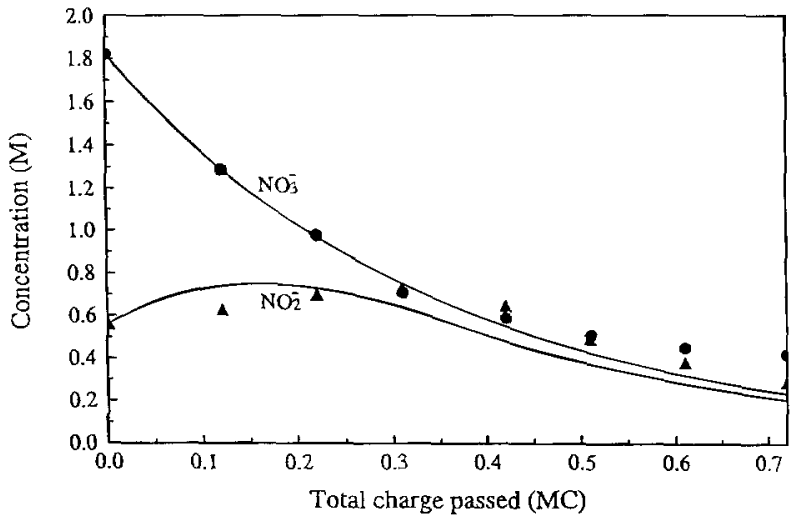

Fig. 5. Comparison of nitrate and nitrite concentration predictions with experimental data as a function of total charge passed. The experiment was performed at a current density of $0.5 \mathrm{~A} / \mathrm{cm}^{2}$. All other parameters are shown in Tables II and III. MC is defined as million coulombs.

crepancy occurs in a region where the cell operation is undesired (i.e., high hydrogen partial currents). The percent difference between the partial current densities predicted by the two models is approximately the same for each reaction, but the absolute difference is the greatest for $\mathrm{NH}_{3}$ production.

Batch simulation results.--In a batch run, changes in species concentrations with time cause movement of ions across the separator. In addition to the single-pass equations $(8,10$, and 14), the time-dependent Eq. 18 must be solved to track the current densities with time. The simulation of the batch cell provides a rough estimate of the energy consumed and the time required for $95 \%$ reduction of nitrates and nitrites. At the cathode, it is desirable to maximize the partial currents for reactions 1 through 4 and minimize the partial current for reaction 5 (production of $\mathrm{H}_{2}$ ). At the anode, it is desirable to maximize the efficiency of reaction 6 (oxidation of $\mathrm{OH}^{-}$) and minimize that of reverse reaction 1 (oxidation of nitrite to nitrate).

Three batch runs were performed, one at a constant current density of $0.5 \mathrm{~A} / \mathrm{cm}^{2}$, and the other two at cell voltages of $3.5 \mathrm{~V}$ (low-voltage run) and $5.65 \mathrm{~V}$ (high-voltage run) The constant-current run is compared to experimental data $^{3}$ to demonstrate the validity of the parameters used in the simulations. For each of the constant-voltage cases, the catholyte recirculation tank volume and anolyte recirculation tank volume were kept at 700 and $7000 \mathrm{ml}$, respectively. During these three batch simulations no attempt was made to optimize the reactor operation.

A comparison of the nitrate and nitrite concentration predictions with experimental data ${ }^{3}$ is shown in Fig. 5 . The

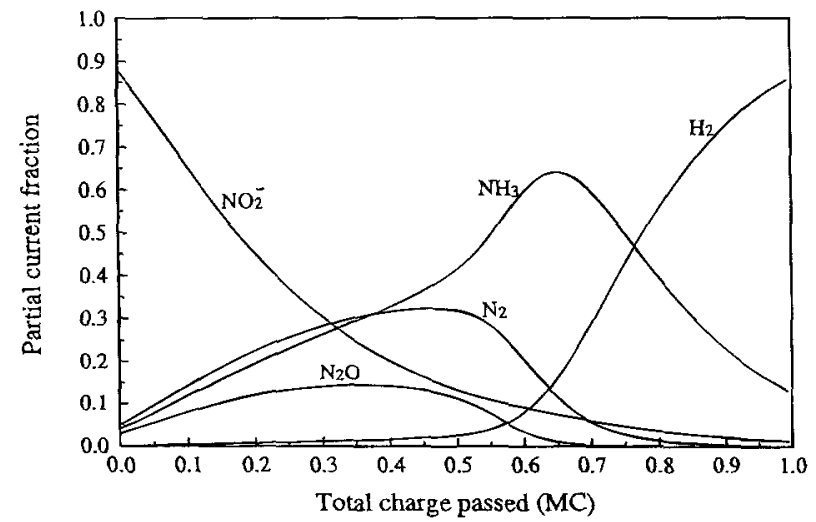

Fig. 6. Partial current fractions for the five cathodic reactions as a function of total charge passed for the low-voltage run. Cell voltage is $3.5 \mathrm{~V}$. Toward the end of the batch run, reaction $5\left(\mathrm{H}_{2}\right.$ production) increases rapidly.

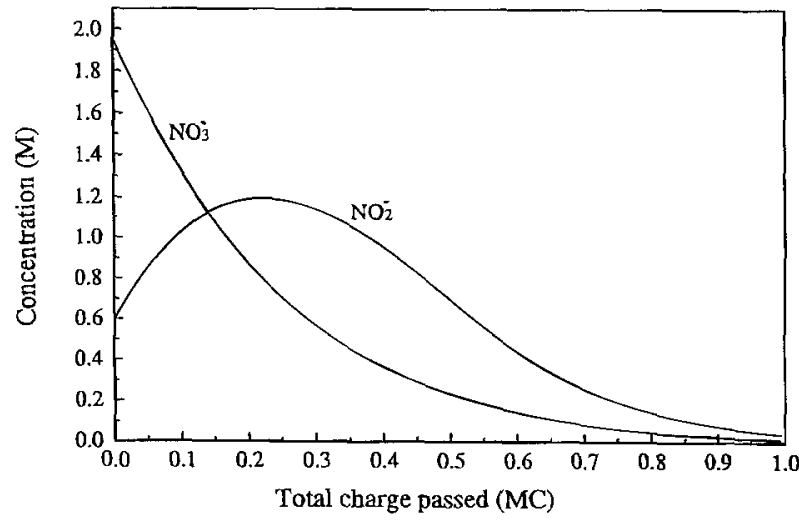

Fig. 7. Ionic concentrations in the catholyte recirculation tank as a function of total charge passed for the low-voltage run. Cell voltage is $3.5 \mathrm{~V}$.

operating parameters for this run are identical to those used in all other simulations, except for the values shown in parentheses in Tables II and III. There is good agreement between the model predictions and data, thus validating the kinetic and physical parameters used in the simulation. Toward the end of the batch run (charge passed $>0.6 \mathrm{MC}$ ) there is some discrepancy which may result from the oversimplified treatment of ion transport across the separator. The composition of the off gas predicted by this simulation also agrees with experimental data. In the first half of the run, the ratio of $\mathrm{N}_{2}: \mathrm{NH}_{3}: \mathrm{N}_{2} \mathrm{O}: \mathrm{H}_{2}$ measured experimentally is about $18: 2: 12: 68$, while the model predicts the ratio to be $18: 2: 12: 51$.

Figure 6 shows a plot of the partial current fractions at the cathode vs. total charge passed for a batch run performed at a constant cell voltage of $3.5 \mathrm{~V}$. The total charge passed is the time integral of the operating current. The initial cell current for the batch run was $0.42 \mathrm{~A} / \mathrm{cm}^{2}$, which corresponds to a potential at the cathode of $-1.1 \mathrm{~V}$ in Fig. 3 through 5. The cell current ranged from a maximum of $0.42 \mathrm{~A} / \mathrm{cm}^{2}$ to a minimum of $0.3 \mathrm{~A} / \mathrm{cm}^{2}$. Initially, nitrate reduction (reaction 1) has the largest partial current fraction. It gradually decreases during the run as the nitrate concentration decreases. In contrast, the fraction of current going into reactions 2 through 5 increases through the first half of the run.

The initial increase in the current associated with reactions 2 through 4 is due to an increase in nitrite concentration which is caused by the high rate of destruction of nitrate (reaction 1). Midway through the run, the nitrite concentration begins to decrease, reducing the rate of reactions 3 and 4 . However, the rate of reaction 2 is not immediately affected (and continues to rise) because its reaction order (defined as the stoichiometric coefficient of $\mathrm{NO}_{2}^{-}$relative to the number of electrons) is much lower than those of reactions 3 and 4 . By the end of the run, little nitrate and nitrite remain, and almost all the current is due to $\mathrm{H}_{2}$ evolution (reaction 5). Even at the end of the run (at low $\mathrm{NO}_{3}^{-}$and $\mathrm{NO}_{2}^{-}$concentrations), the partial current fraction for reaction 2 is high $(\sim 0.2)$. This too can be attributed to the fact that the order of reaction 2 is much lower than the orders of reactions 3 and 4 . This relatively small dependence on the surface $\mathrm{NO}_{2}^{-}$concentration causes the $\mathrm{NH}_{3}$ curve to decrease much more gradually than the $\mathrm{N}_{2}$ and $\mathrm{N}_{2} \mathrm{O}$ curves. The partial current fractions at the anode are not shown since reaction 6 consumes nearly all the current.

Figure 7 shows the ionic concentrations in the catholyte recirculation tank $v s$. charge passed. It can be seen that the concentrations of nitrates and nitrites are reduced $95 \%$ over the course of the run. An initial increase in the nitrite concentration is observed because its rate of production from reaction 1 exceeds its rate of destruction (from reactions 2,3 , and 4). After about $2 \mathrm{~h}$, the nitrite concentration begins to decrease since little is now produced via reaction 1 . The nitrate concentration shows an exponential decrease, the same trend that is seen experimentally. ${ }^{3}$ 


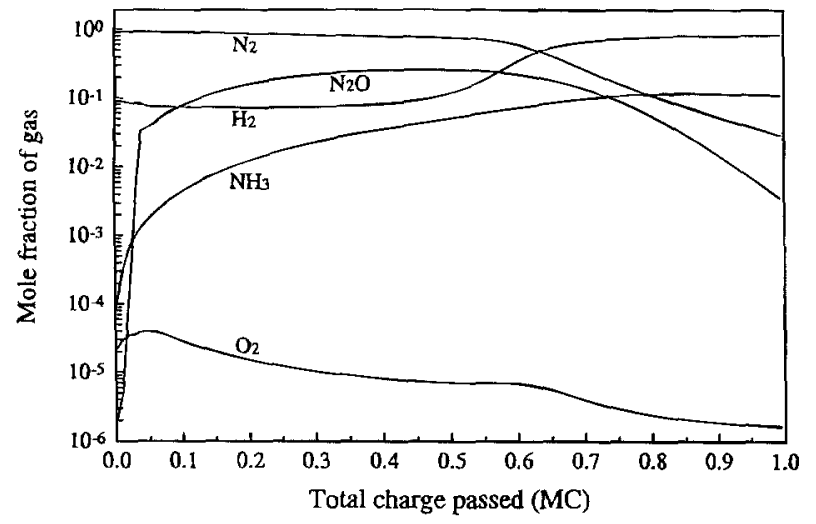

Fig. 8. Off-gas composition from the catholyte recirculation tank as a function of total charge passed for the low-voltage run. Cell voltage is $3.5 \mathrm{~V} . \mathrm{N}_{2}$ is the main component of the off gas during the initial phase of the simulation, while $\mathrm{H}_{2}$ evolution becomes significant during the terminal phase. $\mathrm{NH}_{3}$ and $\mathrm{N}_{2} \mathrm{O}$ are the other major components of the gas phase.

From simulation results, approximately $7.4 \mathrm{~h}$ are needed to destroy $95 \%$ of the nitrates and nitrites. To increase the percent destruction from 95 to $98 \%$ takes an additional $3 \mathrm{~h}$. Therefore, carrying out the reduction beyond $95 \%$ significantly increases the operating cost, which in turn increases the overall cost of treating the waste.

The catholyte off-gas compositions are shown in Fig. 8. It can be seen that $\mathrm{N}_{2}, \mathrm{~N}_{2} \mathrm{O}$, and $\mathrm{H}_{2}$ are the major gases produced at the beginning of the run, even though the partial current fractions for reactions 4 and 5 are lower than those of reaction $2\left(\mathrm{NH}_{3}\right.$ production). This is because the solubility of $\mathrm{NH}_{3}$ is much higher than those of $\mathrm{N}_{2}, \mathrm{~N}_{2} \mathrm{O}$, and $\mathrm{H}_{2}$. The low amount of $\mathrm{O}_{2}$ observed in the catholyte is due to the diffusion of anodically produced oxygen through the separator. Experiments also show a similar trend with regard to the relative amount of each gas generated (i.e., $\mathrm{N}_{2}$ and $\mathrm{H}_{2}$ are the major gases, followed by $\mathrm{N}_{2} \mathrm{O}$ and $\mathrm{NH}_{3}$ ). After most of the nitrates and nitrites are destroyed, hydrogen becomes the major off gas. As a result, the total gas flow rate prediction shows an abrupt rise at around $0.5 \mathrm{MC}$.

Figure 4 illustrates that, for a potential difference at the cathode of $-1.1 \mathrm{~V}$, most of the current is going into reaction 1 with little production of $\mathrm{H}_{2}$. The main objective, however, is to destroy both nitrates and nitrites as quickly as possible and not necessarily minimize the fraction of current going into $\mathrm{H}_{2}$ evolution. Therefore, a batch run at $5.65 \mathrm{~V}$ was performed to investigate the consequence of operating at high destruction rates. The initial current for this run was $1.38 \mathrm{~A} / \mathrm{cm}^{2}$, corresponding to a potential difference at the cathode of $-1.4 \mathrm{~V}$ in Fig. 3 and 4 . The cell current ranged from a maximum of $1.38 \mathrm{~A} / \mathrm{cm}^{2}$ to a minimum of

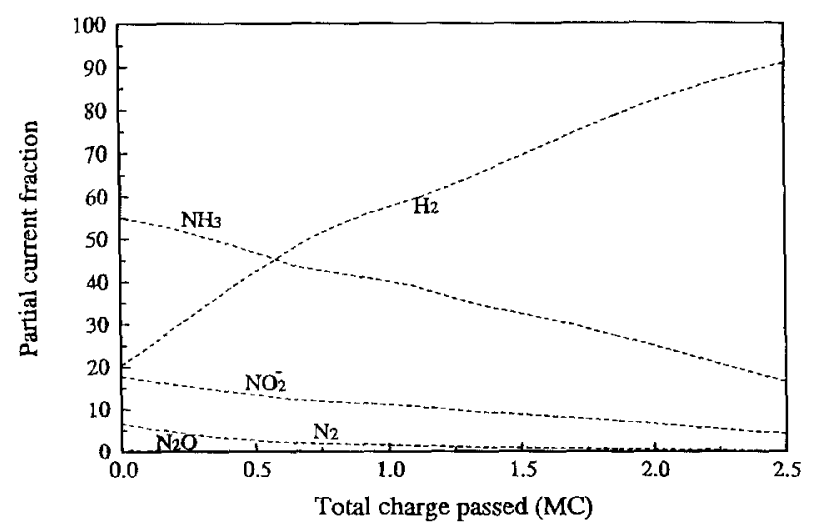

Fig. 9. Partial current fractions for the five cathodic reactions as a function of total charge passed for the high-voltage run. Cell voltage is $5.65 \mathrm{~V}$. It can be seen that most of the current goes into production of $\mathrm{H}_{2}$ at this high voltage.

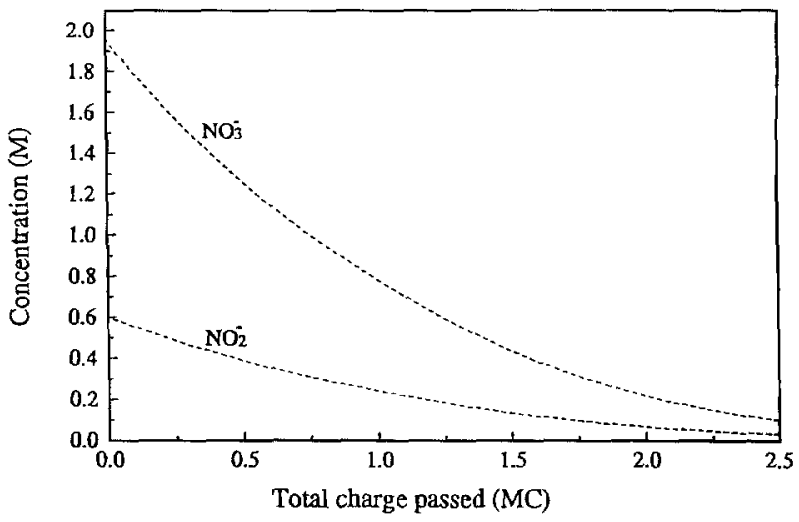

Fig. 10. Ionic concentrations in the catholyte recirculation tank as a function of total charge passed for the high-voltage run. Cell voltage is $5.65 \mathrm{~V}$.

$0.85 \mathrm{~A} / \mathrm{cm}^{2}$. The rest of the parameters were left unchanged. The resulting plots are shown in Fig. 9 through 12.

A plot of the cathodic partial current fractions $v s$. total charge passed is shown in Fig. 9. It can be seen that, except for early in the run when the $\mathrm{NH}_{3}$ production rate is high, most of the cell current goes into $\mathrm{H}_{2}$ production (reaction 5). The high $\mathrm{H}_{2}$ partial current results because reactions 1 through 4 are under mass-transfer control during the entire batch run. This is the reason why no peaks (Fig. 6) are observed. The large rate of $\mathrm{H}_{2}$ production represents a significant amount of energy going into an undesired product. By the end of the run, little nitrate and nitrite remain, and hence the efficiency of reaction 5 is approximately $100 \%$.

Figure 10 shows the ionic concentrations in the catholyte recirculation tank $v s$. charge passed for the high-voltage run. The cell voltage is maintained constant at $5.65 \mathrm{~V}$. Unlike the low-voltage case, the nitrite concentration shows a constant decrease because the rate of nitrite destruction from reactions 2, 3, and 4 is much greater than the rate of production from reaction 1 . This is due to the high current associated with reaction 2 . The catholyte off-gas compositions are shown in Fig. 11. It can be seen that $\mathrm{H}_{2}$ and $\mathrm{NH}_{3}$ are the major gases throughout the run as indicated by the high partial current fractions associated with their production. As mentioned earlier, the large rate of $\mathrm{H}_{2}$ production represents a significant loss of energy, and therefore it must be reduced. This is one reason for performing optimization studies. Again, the low amount of $\mathrm{O}_{2}$ observed in the catholyte is due to the diffusion of anodically produced oxygen through the separator.

As mentioned earlier, to obtain $95 \%$ conversion of the total concentration of nitrates and nitrites at $3.5 \mathrm{~V}$ requires $\sim 7.4 \mathrm{~h}$. At $5.65 \mathrm{~V}$, the processing time is reduced to $6.4 \mathrm{~h}$, but the total required charge passed increases by a factor of 2.5 . This represents increased operating costs.

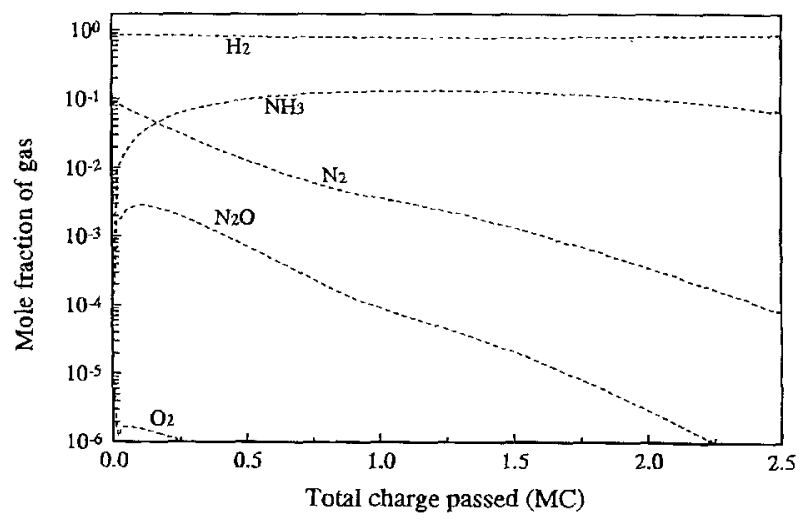

Fig. 11. Off-gas composition from the catholyte recirculation tank as a function of total charge passed for the high-voltage run. Cell voltage is $5.65 \mathrm{~V} . \mathrm{H}_{2}$ is the main component of the off gas throughout the run, while $\mathrm{NH}_{3}$ evolution is significant during the initial phase. 


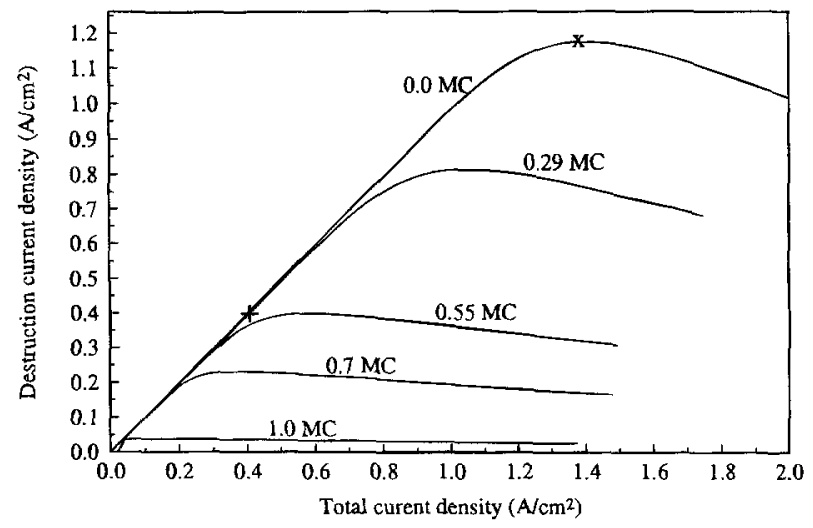

Fig. 12. Destruction current vs. total current from the low-voltage run. The peaks represent the current which maximizes the destruction of nitrates and nitrites at each point in time. + and $X$ denote initial conditions of the low-voltage and high-voltage runs, respectively.

Batch optimization.-The previous sections focused on a batch simulation where the cell voltage was held constant. However, there is an optimal operational path in which the cell voltage (or cell current) is varied over the course of the batch run. We now briefly consider how the model can be used to determine optimal batch cell operation.

To minimize reduction time, we must maximize the destruction current (current going into reactions 1 to 4). Figure 12 shows the plot of destruction current $v s$. total current at different points in time (represented by total charge passed) during the low-voltage batch simulation. A peak in the destruction current on each curve corresponds to the optimum total current with respect to the destruction rate. The gradual decrease in destruction current at high total currents is due to the migrational effect which repels the nitrates and nitrites away from the cathode at high currents, thereby increasing the current going into $\mathrm{H}_{2}$ production (reaction 5). The low-voltage run operates at a low destruction rate throughout most of the batch run; the high-voltage run operates near the maximum destruction rate at the start of the batch run, but moves beyond the maximum after the start of the batch.

Clearly, adjusting the operating current to pass through these maxima throughout the batch minimizes the time to reach $95 \%$ conversion of nitrates and nitrites. However, such a strategy may generate an unacceptable amount of $\mathrm{H}_{2}$. For example, applying an operating current of $1.4 \mathrm{~A} /$ $\mathrm{cm}^{2}$ (the peak destruction rate) at the start of the batch results in $0.2 \mathrm{~A} / \mathrm{cm}^{2}$ going into $\mathrm{H}_{2}$ production. A simple optimization formulation which takes into account $\mathrm{H}_{2}$ production is

$$
\begin{gathered}
\operatorname{Max}\left\{\sum_{j=1}^{4} i_{j}\right\} \\
\text { subject to } \frac{\sum_{j=1}^{4} i_{j}}{\sum_{j=1}^{5} i_{j}} \geq \epsilon_{\mathrm{d}}
\end{gathered}
$$

Equation 21 maximizes the sum of the partial current densities of reactions 1 through 4 and hence maximizes the destruction rate of nitrates and nitrites. The variable $\epsilon_{\mathrm{d}}$ is the destruction efficiency, defined as the ratio of the sum of partial current densities of reactions 1 through 4 to the total current density. The constraint on $\epsilon_{\mathrm{d}}$ puts a limit on $\mathrm{H}_{2}$ evolution and thus provides a trade-off between acceptable $\mathrm{H}_{2}$ production and total processing time.

Figure 13 further illustrates the advantage of operating the batch runs subject to the constraint on $\epsilon_{\mathrm{d}}$. The symbol $\mathrm{o}$ indicates the maximum destruction current subject to $\epsilon_{\dot{d}} \geq$ 0.98 . The symbol $\mathrm{X}$ in the figure corresponds to the maxima from Fig. 12. At the start of the batch run, for example, operating at $1.38 \mathrm{~A} / \mathrm{cm}^{2}$ yields a destruction efficiency of
$82 \%$. Decreasing the total current by $0.38 \mathrm{~A} / \mathrm{cm}^{2}$ results in an increase in destruction efficiency to $98 \%\left(\mathrm{H}_{2}\right.$ production rate decreases by approximately $95 \%$ ) while reducing the destruction rate only by $10 \%$. Also shown in Fig. 13 is the efficiency during the low-voltage run (indicated by the symbol *). Nearly $100 \%$ destruction efficiency was attained during the first half of the batch run, and as a result little $\mathrm{H}_{2}$ was produced. The efficiency dropped to about $10 \%$ by the end of the batch run. Unfortunately, the overall destruction rate was low. By comparison, at the beginning of the batch, the high-voltage case yielded high destruction rates, but only $82 \%$ destruction efficiency. Near the end the batch, this destruction efficiency was around $2 \%$.

\section{Conclusion}

A simple boundary-layer model for the electrochemical destruction of nitrates and nitrites in a parallel-plate reactor has been presented. It includes the effect of potential, ionic migration, electrode kinetics, and flashing of gases in the reactor. The model is suitable for optimization studies and for use in a flowsheet model for the treatment of liquid radioactive wastes. A single-pass calculation of the boundary-layer model shows excellent agreement with the distributed-parameter model prediction in the range of interest, indicating that the transport to the electrode surface can be well characterized by a boundary-layer approximation.

Three batch simulations were run, one to test the validity of the model parameters and the other two to evaluate the effect of cell voltage on the overall destruction rate of nitrate and nitrite. Good agreement between simulated and experimental data (i.e., nitrate and nitrite concentrations and off-gas composition) is observed over the course of the constant-current batch run. For the constant voltage run of $3.5 \mathrm{~V}$, initially a sizable fraction of the total current goes into destroying nitrates and nitrites, but near the end of the batch run almost all the current contributes to $\mathrm{H}_{2}$ evolution. $\mathrm{N}_{2}, \mathrm{~N}_{2} \mathrm{O}$, and $\mathrm{H}_{2}$ are the major gases produced. At a fixed cell voltage of $5.65 \mathrm{~V}$, except for early in the batch run when $\mathrm{NH}_{3}$ production is significant, nearly all of the current goes into $\mathrm{H}_{2}$ evolution. $\mathrm{NH}_{3}$ and $\mathrm{H}_{2}$ are the major gases produced. The overall destruction rate is greater in the high-voltage run than in the low-voltage run. To obtain $95 \%$ conversion of the total concentration of nitrates and nitrates, $7.4 \mathrm{~h}$ are required at $3.4 \mathrm{~V}$ and $6.4 \mathrm{~h}$ at $5.65 \mathrm{~V}$.

A preliminary optimization of the batch reactor shows that at each point in time during the batch there exists an optimum cell voltage (or cell current) which maximizes the overall destruction rate of nitrates and nitrites. To keep hydrogen evolution at reasonable levels (high $\mathrm{H}_{2}$ generation leads to high operating costs and unsafe operating

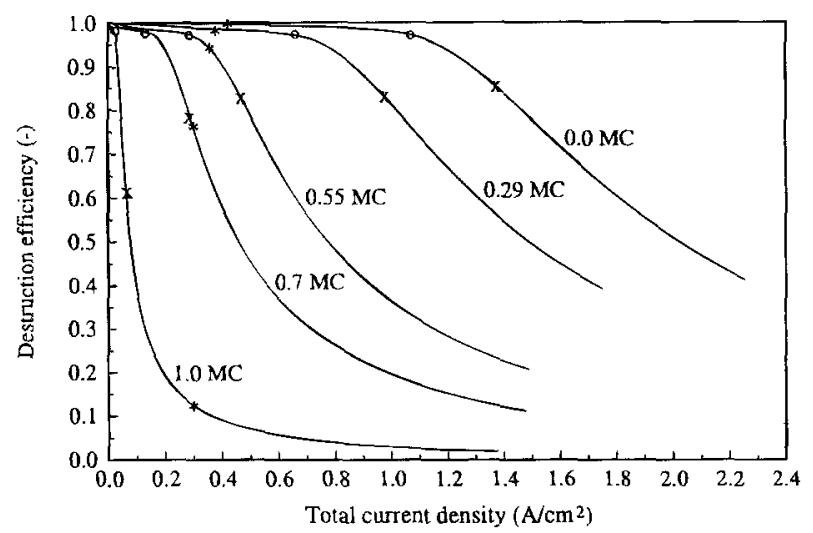

Fig. 13. Destruction current efficiency vs. total current from the low-voltage run. o denotes the optimal operating currents at which the reactor should be operated to maximize the destruction of nitrates and nitrites while preventing unacceptable levels of $\mathrm{H}_{2}$ generation at each point in time. $X$ denotes the position of peaks from Fig. 12. * denotes the destruction efficiency at various times during the low-voltage run. 
conditions), the destruction efficiency must be maintained above a minimum constraint. This optimum cell voltage (or cell current) is a function of nitrate and nitrite concentration and therefore changes as the batch progresses.

\section{Acknowledgment}

This work was funded by the U.S. Department of Energy, Office of Technology Development, Office of Environmental Management through the Efficient Separations and Processing Integrated Program under Contract DE-AC0988SR18035 as task order no. 112 through the SCUREF (South Carolina Universities Research and Education Foundation) Contract No. AA009-00T. The authors gratefully acknowledge this support. The authors also thank Dr. David T. Hobbs for his valuable contribution to this work.

Manuscript submitted May 5, 1995; revised manuscript received July 7, 1995.

University of South Carolina assisted in meeting the publication costs of this article.

\section{LIST OF SYMBOLS}

\section{A electrode area, $\mathrm{cm}^{2}$}

$C_{\mathrm{i}, \text { ref }}$ concentration of oxidized species in reaction $j$ at reference conditions, $\mathrm{mol} / \mathrm{cm}^{3}$

$C_{\mathrm{i}, \mathrm{s}, \mathrm{a}}$ concentration of species $\mathrm{i}$ at the anode surface, $\mathrm{mol} / \mathrm{cm}^{3}$

$C_{1, b, a}$ bulk concentration of species $i$ in the anolyte, $\mathrm{mol} / \mathrm{cm}^{3}$

$C_{i, s, c}$ concentration of species $i$ at the cathode surface, $\mathrm{mol} / \mathrm{cm}^{3}$

$C_{1, b, c}$ bulk concentration of species $i$ in the catholyte, $\mathrm{mol} / \mathrm{cm}^{3}$

$d_{e}$ equivalent diameter of the flow region, $\mathrm{cm}$

$D_{i} \quad$ diffusion coefficient of species $\mathrm{i}, \mathrm{cm}^{2} / \mathrm{s}$

$F \quad$ Faraday's constant, $96,487 \mathrm{C} / \mathrm{mol}$

f $F / \Re T, \mathrm{C} / \mathrm{J}$

$F_{v c}$ outlet flow rate of the vapor phase, $\mathrm{mol} / \mathrm{s}$

$i_{\mathrm{vc}}$ partial current density of reaction $\mathrm{j}, \mathrm{A} / \mathrm{cm}^{2}$

$i_{o, \text { ref }, j}$ exchange current density of reaction $\mathrm{j}, \mathrm{A} / \mathrm{cm}^{2}$

$i_{\mathrm{t}} \quad$ total current density, $\mathrm{A} / \mathrm{cm}^{2}$

$k_{\mathrm{m}, \mathrm{i}} \quad$ mass-transfer coefficient of species $\mathrm{i}, \mathrm{cm} / \mathrm{s}$

$L$ length of the electrochemical reactor, $\mathrm{cm}$

$M_{1} \quad$ species i indicator

$N_{i} \quad$ flux of species i in the boundary layer, $\mathrm{mol} / \mathrm{cm}^{2} \cdot \mathrm{s}$

$N_{i, s} \quad$ flux of species i through the separator, $\mathrm{mol} / \mathrm{cm}^{2} \cdot \mathrm{s}$

$\mathrm{N}_{\mathrm{m}} \quad$ MacMullin number

$n_{j} \quad$ number of electrons taking part in reaction $j$

$p_{i j} \quad$ order of reaction $j$ with respect to reactant $i$

$q_{i j} \quad$ order of reaction $j$ with respect to product $i$

$\Re$ universal gas constant, $8.314 \mathrm{~J} / \mathrm{mol} \mathrm{K}$

Re Reynolds number

$R_{\mathrm{i}} \quad$ rate of generation of species i due to homogeneous reactions, $\mathrm{mol} / \mathrm{s}$

$S \quad$ Electrode gap, $\mathrm{cm}$

$\mathrm{Sc}_{\mathrm{i}} \quad$ Schmidt number for species $\mathrm{i}$

$s_{\mathrm{ij}} \quad$ stoichiometric coefficient of species $\mathrm{i}$ in reaction $\mathrm{j}$

$U^{\theta} \quad$ thermodynamic potential of the reaction at standard conditions, $\mathrm{V}$

$U_{j}^{\text {ref }}$ thermodynamic potential of the reaction at reference conditions, $\mathrm{V}$

$v \quad$ velocity of the fluid flow, $\mathrm{cm} / \mathrm{s}$

$V_{\mathrm{a}} \quad$ potential of the metal anode, $\mathrm{V}$

$V_{c}$ potential of the metal cathode, $V$

$V_{\text {ca }}$ volume of the catholyte compartment of the cell, $\mathrm{cm}^{3}$

$V_{\text {res }}$ volume of the catholyte recirculation tank, $\mathrm{cm}^{3}$ $y_{1, c} \quad$ mole fraction of species i in the vapor phase

$z_{i} \quad$ charge carried by species i

Subscripts

a anolyte region

b bulk conditions

c catholyte region

f feed stream

i species

j reaction

ref reference conditions

res conditions in the reservoir

$\mathrm{s}$ conditions at the electrode surface

Greek

$\alpha_{a} \quad$ anodic transfer coefficient

$\alpha_{c} \quad$ cathodic transfer coefficient

$\delta_{i} \quad$ diffusion length, $\mathrm{cm}$

$\delta_{\mathrm{s}} \quad$ separator thickness, $\mathrm{cm}$

$\boldsymbol{\epsilon}_{\tilde{d}}$ destruction efficiency for optimization purposes

$\gamma_{\mathrm{i}} \quad\left(z_{1} F i_{\mathrm{t}}\right) /\left(\Re T \kappa_{\mathrm{c}}\right), \mathrm{cm}^{-1}$

$\eta_{\mathrm{xe}, \mathrm{j}}$ overpotential of reaction $\mathrm{j}$ at reference conditions, $\mathrm{V}$

$\mathrm{K}_{\mathrm{a}}$ conductivity of the anolyte, $\Omega^{-1} \mathrm{~cm}^{-1}$

$\kappa_{c} \quad$ conductivity of the catholyte, $\Omega^{-1} \mathrm{~cm}^{-1}$

$\kappa_{\mathrm{s}}$ conductivity of the separator, $\Omega^{-1} \mathrm{~cm}^{-1}$

$y \quad$ kinematic viscosity of the fluid, $\mathrm{cm}^{2} / \mathrm{s}$

$\phi$ potential in the electrolyte, $\mathrm{V}$

\section{REFERENCES}

1. D. T. Hobbs, Electrochemistry for a Cleaner Environment, J. D. Genders and N. L. Weinberg, Editors, The Electrosynthesis Company, Amherst, New York (1992).

2. D. T. Hobbs and M. Ebra, AIChE Symp. Series No. 254, 83, 149 (1987).

3. J. D. Genders, N. L. Weinberg, and D. Hartsough, Phase II Report, WSRC TR 90 491(1992).

4. D. Coleman, R. E. White, and D. T. Hobbs, This Journal, 142, 1152 (1995)

5. W. R. Parrish and J. S. Newman, ibid., 117, 43 (1970).

6. G. Sakellaropoulos and G. Francis, ibid,, 126, 1928 (1979).

7. V. Edwards and J. S. Newman, ibid., 134, 1181 (1987).

8. R. E. White, M. Bain, and M. Raible, ibid., 130, 1037 (1983).

9. J. S. Newman, Electrochemical Systems, 2nd ed., Prentice Hall, Englewood Cliffs, NJ (1991).

10. M. J. Mader, C. W. Walton, and R. E. White, This Journal, 133, 1124 (1986).

11. R. Caban and T. W. Chapman, Chem. Eng. Sci., 36, 849 (1981).

12. J. Lee and J. R. Selman, This Journal, 129, 1670 (1982).

13. J. C. Smeltzer and P. S. Fedkiw, ibid., 139, 1358 (1992).

14. J. C. Smeltzer and P. S. Fedkiw, ibid., 138, 3665 (1991).

15. T. V. Nguyen, C. W. Walton, and R. E. White, ibid., 133, 1130 (1986).

16. J. C. Smeltzer and P. S. Fedkiw, ibid., 139, 1366 (1992).

17. D. J. Pickett, Electrochemical Reactor Design, 2nd ed., Elsevier Scientific, New York (1979).

18. D. T. Hobbs, J. D. Genders, and D. Hartsough, Abstract 568, p. 910, The Electrochemical Society Extended Abstracts, Vol. 94-1, San Francisco, CA, May 22-27, 1994.

19. D. Fan and R. E. White, This Journal, 138, 2952 (1991).

20. J. W. Van Zee, A. T. Watson, and R. E. White, ibid., 133, 501 (1986).

21. A. Fredenslund, R. L. Jones, and J. M. Prausnitz, AIChE J., 21, 1086 (1975). 